\title{
Parabacteroides johnsonii sp. nov., isolated from human faeces
}

\author{
Mitsuo Sakamoto, Maki Kitahara and Yoshimi Benno \\ Microbe Division/Japan Collection of Microorganisms, RIKEN BioResource Center, Wako, \\ Saitama 351-0198, Japan
}

Correspondence

Mitsuo Sakamoto

sakamoto@jcm.riken.jp

\begin{abstract}
A bacterial strain isolated from human faeces, $\mathrm{M}-165^{\top}$, was characterized in terms of its phenotypic and biochemical features, cellular fatty acid profile, menaquinone profile and phylogenetic position (based on 16S rRNA gene sequence analysis). A 16S rRNA gene sequence analysis showed that the isolate was a member of the genus Parabacteroides. Strain $\mathrm{M}-165^{\top}$ was closely related to Parabacteroides merdae strains, showing $98 \%$ sequence similarity. The strain was obligately anaerobic, non-pigmented, non-spore-forming, non-motile, Gram-negative, rod-shaped and was able to grow on media containing $20 \%$ bile. Although the phenotypic characteristics of the strain $\mathrm{M}-165^{\top}$ were similar to those of $P$. merdae, the isolate could be differentiated from $P$. merdae by means of API 20A tests for L-arabinose and L-rhamnose fermentation. DNA-DNA hybridization experiments revealed the genomic distinctiveness of the novel strain with respect to $P$. merdae JCM $9497^{\top}$ ( $\leqslant 60 \%$ DNA-DNA relatedness). The DNA G $+\mathrm{C}$ content of the strain is $47.6 \mathrm{~mol} \%$. On the basis of these data, strain $\mathrm{M}-165^{\top}$ represents a novel species of the genus Parabacteroides, for which the name Parabacteroides johnsonii sp. nov. is proposed. The type strain is $\mathrm{M}-165^{\top}$ $\left(=\mathrm{JCM} 13406^{\top}=\mathrm{DSM} 18315^{\top}\right)$.
\end{abstract}

Members of the genus Bacteroides are a predominant component of human faecal microbiota. Although many species were originally included in this group, the taxonomy of the genus Bacteroides has undergone significant changes in the last decade (Jousimies-Somer \& Summanen, 2002). Consequently, some species that were not included in Bacteroides sensu stricto (Shah \& Collins, 1989) have been transferred to novel genera, such as Alistipes (Rautio et al., 2003), Dialister (Moore \& Moore, 1994), Dichelobacter (Dewhirst et al., 1990) and Tannerella (Sakamoto et al., 2002). More recently, the misclassified species Bacteroides distasonis (Eggerth \& Gagnon, 1933), Bacteroides goldsteinii (Song et al., 2005) and Bacteroides merdae (Johnson et al., 1986) were ultimately reclassified as Parabacteroides distasonis, Parabacteroides goldsteinii and Parabacteroides merdae (Sakamoto \& Benno, 2006). In the process of collecting P. merdae JCM 13405 (Sakamoto \& Benno, 2006), we found a $P$. merdae-like strain isolated from human faeces that was not identified as $P$. merdae by a PCR technique using species-specific primers (Liu et al., 2003). The present study was designed to determine the taxonomic status of this strain.

\footnotetext{
The GenBank/EMBL/DDBJ accession number for the 16S rRNA gene sequence of strain $M-165^{\top}$ is $A B 261128$.

The cellular fatty acid compositions of strain $M-165^{\top}$ and closely related species are available in a supplementary table in IJSEM Online.
}

The strains used in the present study were maintained for 2 days at $37^{\circ} \mathrm{C}$ under $\mathrm{CO}_{2}$ on Eggerth Gagnon (EG) agar (Merck) supplemented with $5 \%(\mathrm{v} / \mathrm{v})$ horse blood. Strain $\mathrm{M}-165^{\mathrm{T}}$ was isolated from human faeces. Bacteroides bileaesculin agar (Shah, 1992) was used to check whether the growth of the isolate was inhibited on this medium. A PCR technique involving species-specific primers (Liu et al., 2003) was used to identify the $P$. merdae-like strain, as described previously (Sakamoto \& Benno, 2006). Physiological reactions were determined with an API 20A anaerobe test kit (in duplicate) as recommended by the manufacturer (bioMérieux). The metabolic end products were prepared as described by Holdeman et al. (1977) and were analysed as described previously (Sakamoto et al., 2005). Fatty acid methyl esters were obtained from wet cells (approx. $40 \mathrm{mg}$ ) by saponification, methylation and extraction using the method of Miller (1982) with minor modifications (Kuykendall et al., 1988). Cellular fatty acid profiles were determined by using the MIDI microbial identification system (Microbial ID). Isoprenoid quinones were extracted as described by Komagata \& Suzuki (1987) and were analysed as described previously (Sakamoto et al., 2002). Biochemical reactions were determined with the Rapid ID 32A anaerobe identification kit (in duplicate) as recommended by the manufacturer (bioMérieux). Chromosomal DNA was isolated by using methods described previously (Marmur, 1961; Saito \& Miura, 1963), but with some modifications. The DNA G $+C$ 
content was determined by using the HPLC method of Tamaoka \& Komagata (1984). The elution solvent was a mixture of $0.02 \mathrm{M} \mathrm{NH}_{4} \mathrm{H}_{2} \mathrm{PO}_{4}$ and acetonitrile $(20: 1, \mathrm{v} / \mathrm{v})$. DNA-DNA hybridization experiments were carried out in microplate wells as described by Ezaki et al. (1989). Hybridization was performed at $44^{\circ} \mathrm{C}$ for $16 \mathrm{~h}$. The $16 \mathrm{~S}$ rRNA gene sequence was analysed as described previously (Sakamoto et al., 2002). Related sequences were aligned with the CLUSTAL W program (Thompson et al., 1994) and corrected by manual inspection. Nucleotide substitution rates ( $K_{\text {nuc }}$ values) were calculated (Kimura, 1980) after gaps and unknown bases had been eliminated. The phylogenetic tree was constructed by using the neighbour-joining method (Saitou \& Nei, 1987). A bootstrap resampling analysis (Felsenstein, 1985) was performed to estimate the confidence of the tree topologies.

Strain $\mathrm{M}-165^{\mathrm{T}}$ was obligately anaerobic, non-pigmented, non-spore-forming, non-motile, Gram-negative and rodshaped; it was not identified as P. merdae by the PCR. Growth of the isolate was not inhibited on medium containing $20 \%$ bile. Cells on EG agar were $0.8 \mu \mathrm{m}$ by $1.7-2.5 \mu \mathrm{m}$ in size and occurred singly. On EG agar plates, colonies were $1-2 \mathrm{~mm}$ in diameter, grey to off-white in colour, circular, entire, slightly convex and smooth. The phenotypic characteristics are given in the species description. The isolate could be differentiated from P. merdae by the ability of the former to ferment L-arabinose and L-rhamnose in the API 20A panel. Catalase production was a key characteristic for differentiating the isolate (and P. distasonis) from P. merdae. Biochemical characteristics of the isolate determined using the Rapid ID 32A kit were similar to those of P. merdae (Sakamoto \& Benno, 2006); only pyroglutamic acid arylamidase activity was different from P. merdae.
The major cellular fatty acids of the isolate were anteiso$15: 0$ and iso-17:0 $3-\mathrm{OH}$ (32 and $21 \%$, respectively). The amount of $18: 1 \omega 9 c(9 \%)$ present was slightly lower than that found in Parabacteroides species (14-16\%), while the amount of $15: 0(5.5 \%)$ present was slightly higher than that found in Parabacteroides species (1.3-3.1\%) (see Supplementary Table S1 available in IJSEM Online).

The major menaquinones of the isolate were MK-9 (54\%) and MK-10 (39\%). A small amount of MK-8 (5\%) was also present. These data are in agreement with the description of the genus Parabacteroides (Sakamoto \& Benno, 2006). The menaquinone compositions of strain $\mathrm{M}-165^{\mathrm{T}}$ and P. merdae JCM $9497^{\mathrm{T}}$ were almost the same.

Approximately 1500 bases of the 16S rRNA gene sequence were determined for the isolate. For the phylogenetic analysis, $1340 \mathrm{bp}$ (positions 61-1375; Escherichia coli numbering system) sequences of each strain were used. The 16S rRNA gene sequence analysis showed that strain $\mathrm{M}-165^{\mathrm{T}}$ represented a species within the genus Parabacteroides (Fig. 1), being closely related to P. merdae (similarities of 97.9 and $98 \%$ for JCM $9497^{\mathrm{T}}$ and JCM 13405, respectively).

The DNA G + C content of strain $\mathrm{M}-165^{\mathrm{T}}$ was $47.6 \mathrm{~mol} \%$. This value is almost the same as those for the reference strains (Table 1). The levels of DNA-DNA relatedness observed serve to distinguish strain $\mathrm{M}-165^{\mathrm{T}}$ genomically from P. merdae JCM $9497^{\mathrm{T}}$ and JCM 13405 (relatively high DNA-DNA relatedness, $\leqslant 60 \%$; Table 1$)$.

On the basis of the above-mentioned findings and the $16 \mathrm{~S}$ rRNA gene sequence analysis, strain $\mathrm{M}-165^{\mathrm{T}}$ represents a novel species of the genus Parabacteroides, for which the name Parabacteroides johnsonii sp. nov. is proposed. The

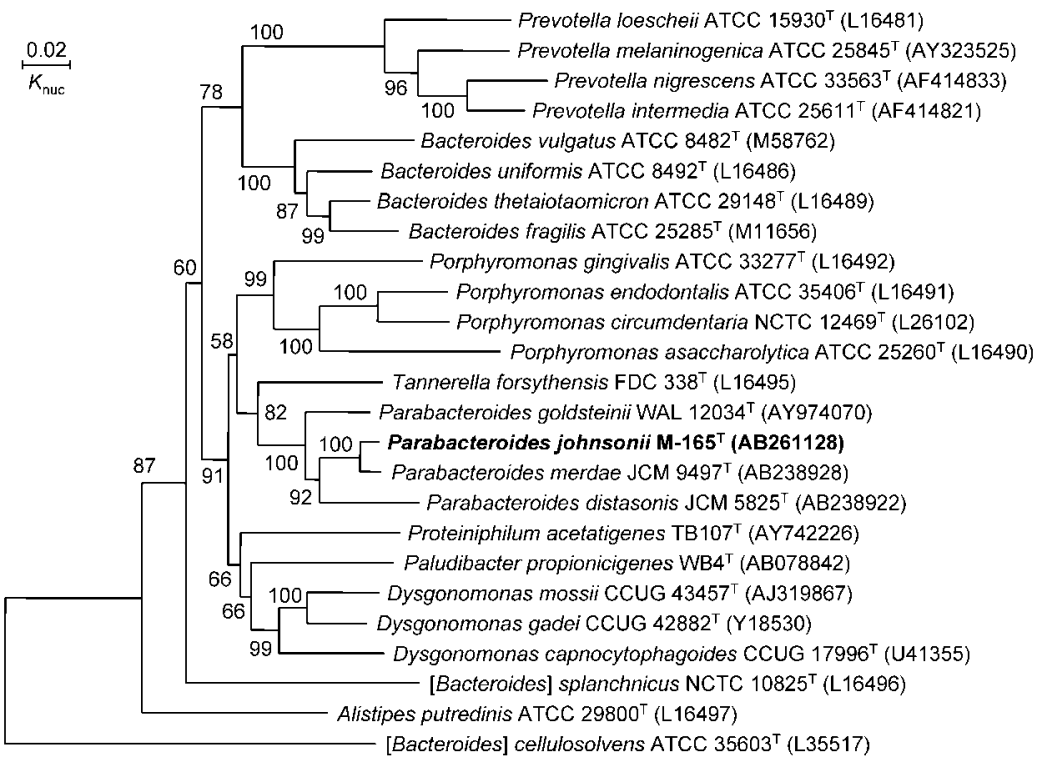

Fig. 1. Neighbour-joining phylogenetic tree, based on 16S rRNA gene sequences, showing the relationship between strain $\mathrm{M}-165^{\mathrm{T}}$ and related species. Accession numbers are shown in parentheses. Numbers at nodes indicate bootstrap percentages from 1000 replicates. Bar, 0.02 substitutions per nucleotide position. 
Table 1. DNA $G+C$ contents and levels of DNA-DNA relatedness

\begin{tabular}{|lcrrrrr|}
\hline Strain & $\begin{array}{c}\text { G+C content } \\
(\mathbf{m o l} \%)\end{array}$ & \multicolumn{5}{c|}{ DNA-DNA relatedness (\%) with: } \\
\cline { 3 - 7 } & & $\mathbf{1}$ & $\mathbf{2}$ & $\mathbf{3}$ & $\mathbf{4}$ & $\mathbf{5}$ \\
\hline 1. Strain M-165 & & 100 & 60 & 59 & 6 & 11 \\
2. P. merdae JCM 9497 & 47.6 & 58 & 100 & 90 & 7 & 4 \\
3. P. merdae JCM 13405 & 47.2 & 60 & 91 & 100 & 8 & 4 \\
4. P. distasonis JCM 5825 & 47.5 & 13 & 15 & 16 & 100 & 9 \\
5. P. goldsteinii JCM 13446 & 47.1 & 12 & 8 & 8 & 4 & 100 \\
\hline
\end{tabular}

Table 2. Differential characteristics of strain $\mathrm{M}-165^{\top}$ (Parabacteroides johnsonii sp. nov.) and other Parabacteroides species

+, Positive; -, negative; V, variable. Data for P. goldsteinii were taken from Song et al. (2005) and this study.

\begin{tabular}{|c|c|c|c|c|}
\hline Characteristic & Strain $M-165^{\mathrm{T}}$ & P. merdae & P. distasonis & P. goldsteinii \\
\hline Catalase production & + & - & + & $\mathrm{V}$ \\
\hline \multicolumn{5}{|l|}{ Acid production from: } \\
\hline Salicin & - & - & + & - \\
\hline L-Arabinose & + & - & - & - \\
\hline D-Cellobiose & - & - & + & + \\
\hline D-Melezitose & - & - & + & - \\
\hline L-Rhamnose & + & - & + & + \\
\hline \multicolumn{5}{|l|}{ Enzyme activities: } \\
\hline$\beta$-Glucosidase & - & - & + & + \\
\hline$\beta$-Glucuronidase & + & + & - & + \\
\hline Pyroglutamic acid arylamidase & - & + & - & - \\
\hline
\end{tabular}

differential characteristics of $P$. johnsonii sp. nov. and other Parabacteroides species are shown in Table 2.

\section{Description of Parabacteroides johnsonii sp. nov.}

Parabacteroides johnsonii (john.so'ni.i. N.L. gen. n. johnsonii of Johnson, named after the American molecular taxonomist John L. Johnson, who was the first to describe $P$. merdae).

Cells are obligately anaerobic, non-spore-forming, nonmotile, Gram-negative rods $(0.8 \times 1.7-2.5 \mu \mathrm{m})$. On EG agar plates, colonies are 1-2 $\mathrm{mm}$ in diameter, grey to off-white in colour, circular, entire, slightly convex and smooth. Indole and urease are not produced. Catalase is produced. Aesculin is hydrolysed. Gelatin is not digested. Grows on medium containing $20 \%$ bile. Acid is produced from L-arabinose, glucose, lactose, maltose, D-mannose, D-raffinose, L-rhamnose, sucrose, D-trehalose and D-xylose but not from D-cellobiose, glycerol, D-mannitol, D-melezitose, salicin or D-sorbitol. Positive Rapid ID 32A reactions are obtained for $\alpha$-galactosidase, $\beta$-galactosidase, $\alpha$-glucosidase, $\alpha$-arabinosidase, $\beta$-glucuronidase, $N$-acetyl- $\beta$-glucosaminidase, glutamic acid decarboxylase, alkaline phosphatase, arginine arylamidase, leucyl glycine arylamidase, phenylalanine arylamidase, leucine arylamidase, tyrosine arylamidase, alanine arylamidase, glycine arylamidase, histidine arylamidase, glutamyl glutamic acid arylamidase and serine arylamidase. Mannose and raffinose are fermented. All of the other tests (for urease, arginine dihydrolase, 6-phospho$\beta$-galactosidase, $\beta$-glucosidase, $\alpha$-fucosidase, nitrate reduction, indole production, proline arylamidase and pyroglutamic acid arylamidase) are negative. The major end products from PYG broth cultures ( $1 \%$ peptone, $1 \%$ yeast extract, $1 \%$ glucose) are succinic and acetic acids; small amounts of isovaleric acid and propionic acid are also produced. The major cellular fatty acids are anteiso15:0 and iso-17:0 3-OH. The predominant respiratory quinones are menaquinones MK-9 and MK-10. The DNA $\mathrm{G}+\mathrm{C}$ content of the type strain is $47.6 \mathrm{~mol} \%$.

The type strain, M-165 ${ }^{\mathrm{T}}\left(=\mathrm{JCM} 13406^{\mathrm{T}}=\mathrm{DSM} 18315^{\mathrm{T}}\right.$ ), was isolated from human faeces.

\section{References}

Dewhirst, F. E., Paster, B. J., La Fontaine, S. \& Rood, J. I. (1990). Transfer of Kingella indologenes (Snell and Lapage 1976) to the genus Suttonella gen. nov. as Suttonella indologenes comb. nov.; transfer of 
Bacteroides nodosus (Beveridge 1941) to the genus Dichelobacter gen. nov. as Dichelobacter nodosus comb. nov.; and assignment of the genera Cardiobacterium, Dichelobacter, and Suttonella to Cardiobacteriaceae fam. nov. in the gamma division of Proteobacteria on the basis of $16 \mathrm{~S}$ rRNA sequence comparisons. Int J Syst Bacteriol 40, 426-433.

Eggerth, A. H. \& Gagnon, B. H. (1933). The Bacteroides of human feces. J Bacteriol 25, 389-413.

Ezaki, T., Hashimoto, Y. \& Yabuuchi, E. (1989). Fluorometric deoxyribonucleic acid-deoxyribonucleic acid hybridization in microdilution wells as an alternative to membrane filter hybridization in which radioisotopes are used to determine genetic relatedness among bacterial strains. Int J Syst Bacteriol 39, 224-229.

Felsenstein, J. (1985). Confidence limits on phylogenies: an approach using the bootstrap. Evolution 39, 783-791.

Holdeman, L. V., Cato, E. P. \& Moore, W. E. C. (1977). Anaerobe Laboratory Manual, 4th edn. Blacksburg, VA: Virginia Polytechnic Institute and State University.

Johnson, J. L., Moore, W. E. C. \& Moore, L. V. H. (1986). Bacteroides caccae sp. nov., Bacteroides merdae sp. nov., and Bacteroides stercoris sp. nov. isolated from human feces. Int J Syst Bacteriol 36, 499-501.

Jousimies-Somer, H. \& Summanen, P. (2002). Recent taxonomic changes and terminology update of clinically significant anaerobic gram-negative bacteria (excluding spirochetes). Clin Infect Dis $\mathbf{3 5}$ (Suppl. 1), S17-S21.

Kimura, M. (1980). A simple method for estimating evolutionary rates of base substitutions through comparative studies of nucleotide sequences. J Mol Evol 16, 111-120.

Komagata, K. \& Suzuki, K. (1987). Lipid and cell-wall analysis in bacterial systematics. Methods Microbiol 19, 161-207.

Kuykendall, L. D., Roy, M. A., O’Neill, J. J. \& Devine, T. E. (1988). Fatty acids, antibiotic resistance, and deoxyribonucleic acid homology groups of Bradyrhizobium japonicum. Int J Syst Bacteriol 38, 358-361.

Liu, C., Song, Y., McTeague, M., Vu, A. W., Wexler, H. \& Finegold, S. M. (2003). Rapid identification of the species of the Bacteroides fragilis group by multiplex PCR assays using group- and speciesspecific primers. FEMS Microbiol Lett 222, 9-16.

Marmur, J. (1961). A procedure for the isolation of deoxyribonucleic acid from microorganisms. J Mol Biol 3, 208-218.

Miller, L. T. (1982). Single derivatization method for routine analysis of bacterial whole-cell fatty acid methyl esters, including hydroxy acids. J Clin Microbiol 16, 584-586.

Moore, L. V. H. \& Moore, W. E. C. (1994). Oribaculum catoniae gen. nov., sp. nov.; Catonella morbi gen. nov., sp. nov.; Hallella seregens gen. nov., sp. nov.; Johnsonella ignava gen. nov., sp. nov.; and Dialister pneumosintes gen. nov., comb. nov., nom. rev., anaerobic gram-negative bacilli from the human gingival crevice. Int J Syst Bacteriol 44, 187-192.

Rautio, M., Eerola, E., Väisänen-Tunkelrott, M. L., Molitoris, D., Lawson, P., Collins, M. D. \& Jousimies-Somer, H. (2003). Reclassification of Bacteroides putredinis (Weinberg et al. 1937) in a new genus Alistipes gen. nov., as Alistipes putredinis comb. nov., and description of Alistipes finegoldii sp. nov., from human sources. Syst Appl Microbiol 26, 182-188.

Saito, H. \& Miura, K. (1963). Preparation of transforming deoxyribonucleic acid by phenol treatment. Biochim Biophys Acta 72, 619-629.

Saitou, N. \& Nei, M. (1987). The neighbor-joining method: a new method for reconstructing phylogenetic trees. Mol Biol Evol 4, 406-425.

Sakamoto, M. \& Benno, Y. (2006). Reclassification of Bacteroides distasonis, Bacteroides goldsteinii and Bacteroides merdae as Parabacteroides distasonis gen. nov., comb. nov., Parabacteroides goldsteinii comb. nov. and Parabacteroides merdae comb. nov. Int J Syst Evol Microbiol 56, 1599-1605.

Sakamoto, M., Suzuki, M., Umeda, M., Ishikawa, I. \& Benno, Y. (2002). Reclassification of Bacteroides forsythus (Tanner et al. 1986) as Tannerella forsythensis corrig., gen. nov., comb. nov. Int J Syst Evol Microbiol 52, 841-849.

Sakamoto, M., Huang, Y., Umeda, M., Ishikawa, I. \& Benno, Y. (2005). Prevotella multiformis sp. nov., isolated from human subgingival plaque. Int J Syst Evol Microbiol 55, 815-819.

Shah, H. N. (1992). The genus Bacteroides and related taxa. In The Prokaryotes, 2nd edn, pp. 3593-3607. Edited by A. Balows, H. G. Trüper, M. Dworkin, W. Harder \& K. H. Schleifer. New York: Springer.

Shah, H. N. \& Collins, M. D. (1989). Proposal to restrict the genus Bacteroides (Castellani and Chalmers) to Bacteroides fragilis and closely related species. Int J Syst Bacteriol 39, 85-87.

Song, Y., Liu, C., Lee, J., Bolanos, M., Vaisanen, M. L. \& Finegold, S. M. (2005). "Bacteroides goldsteinii sp. nov." isolated from clinical specimens of human intestinal origin. J Clin Microbiol 43, 4522-4527.

Tamaoka, J. \& Komagata, K. (1984). Determination of DNA base composition by reversed-phase high-performance liquid chromatography. FEMS Microbiol Lett 25, 125-128.

Thompson, J. D., Higgins, D. G. \& Gibson, T. J. (1994). CLUSTAL W: improving the sensitivity of progressive multiple sequence alignment through sequence weighting, position-specific gap penalties and weight matrix choice. Nucleic Acids Res 22, 4673-4680. 